\title{
Evaluation the professional Practice of community pharmacists in dealing with important drug interactions in prescription
}

\author{
Amir Larki-Harchegani ${ }^{1}$, Maryam Mehrpooya ${ }^{2}$, Amjad Qadermazi $^{2}$, Somayeh Shabib ${ }^{3}$, Sara Ataei ${ }^{*}$ \\ 'Department of Pharmacology and Toxicology, School of pharmacy, Hamadan University of Medical Sciences, Hamadan, Iran. \\ ${ }^{2}$ Department of Clinical Pharmacy, School of Pharmacy, Hamadan University of Medical Sciences, Hamadan, Iran. \\ ${ }^{3}$ Department of Clinical Pharmacy and Pharmacy Practice, School of Pharmacy, Isfahan University of Medical Sciences, Isfahan, Iran.
}

\section{ARTICLE INFO \\ Article history: \\ Received on: 22/12/2017 \\ Accepted on: 24/04/2018 \\ Available online: $30 / 05 / 2018$}

\section{Key words:}

drug interactions,

pharmacists, drug

consulting, Prescription, Iran.

\begin{abstract}
Introduction: Pharmacists play an important role in promoting the public health by optimizing the use of medications through effective communication between the patient and the physician. It is important to assess the scientific capability and accuracy of pharmacists in identifying and correcting possible drug errors in the manuscript. The purpose of this research is to assess the extent of success of pharmacists in performing their professional tasks and determine the important factors involved in this issue. Methods: In this descriptive cross-sectional study, 82 pharmacies were selected to be assessed on their performance in Hamadan city. A trained person with a prescription containing important drug interactions presented to the pharmacies. After delivering the prescription to the pharmacist, a questionnaire was used to assess the levels of pharmacists' participation in drug consulting. Results: The results of this study indicated that pharmacists were present only in 67 pharmacies $(81.7 \%) .27$ pharmacists $(40.3 \%)$ asked the patient's reason for visiting a physician. 22 pharmacists $(32.8 \%)$ paid attention to the drug interactions with warfarin. 63 pharmacists $(94.0 \%)$ gave advice about the proper time of drug taking. Conclusions: Although the pharmacists have sufficient knowledge, they showed poor attention and this issue must strongly be considered.
\end{abstract}

\section{INTRODUCTION}

Medication errors are described as the preventable unsuitable use of medications which can happen at any point in the steps of ordering, transcribing, distributing and consuming of medications. Despite the fact that healthcare systems in Iran claim that medication errors are critical problems in treatment, but because the lack of consistent and accurate statistics, unfortunately, the correct estimate of the number of injuries and costs incurred on health-care systems is not possible (Valizadeh et al., 2008). About $50 \%$ of medication errors are because of physicians' mistakes. Nurses and pharmacists have important roles in medication errors. After physicians, pharmacists are the second line of protection against medication errors. They have significant roles in reviewing prescriptions and evaluating possible drug errors (Hughes and Ortiz, 2005).

"Corresponding Author

Sara Ataei, Department of Clinical Pharmacy, School of Pharmacy,

Hamadan University of Medical Sciences, Hamadan, Iran.

E-mail:s.ataei@umsha.ac.ir
Drug interactions are one of the most important medication errors in prescription. It is often necessary for patients that take more than one medication for full recovery according to the type and severity of the disease. The use of multiple medications (polypharmacy) is prevalent, showing the importance of paying special attention to drug-drug interactions (DDI) during the treatment process. In addition to DDI, drug interactions with foods (FDI) and/or herbal medications are also important in the pharmacological performance of the drugs (Alizadeh et al., 2011). DDI is defined as the change in pharmacological response to a drug because of the interfering effects of other drugs (De Almeida et al., 2007). This can occur in the two forms of pharmacokinetic and pharmacodynamic interactions. In the pharmacokinetic interactions, the drugs' mechanism of action (absorption, distribution, metabolism, and excretion) is changed in the molecular levels which lead to change in pharmacological response to the drug. Pharmacodynamics interactions are a result of agonistic and antagonistic effects of drugs on the same receptors (Pleuvry, 2005; Mehrpooya et al., 2017).

Contrary to the opinion of many people that the pharmacist's duty is limited only to administration and sale of 
drugs, the pharmacists' performance in drug consulting, advice and assessing possible drug interactions are very important in the treatment of patients. Some studies reported that although pharmacists have sufficient knowledge about the use of the medications, they showed poor attention to drug interactions (Mostafavi et al., 2013).

Due to the role of pharmacists in patients' treatment process and the increasing prevalence of polypharmacy, it seems that further training of pharmacists can prevent drug interactions and diminish their effects on patient's mental and physical complications. Therefore, the current study was performed to evaluate the professional functioning of pharmacists against drug interactions in pharmacies of Hamadan city.

\section{METHODS}

\section{Subjects and study design}

This descriptive cross-sectional study was performed to determine pharmacists' performance against drug interactions in 82 pharmacies in Hamadan city in 2016. The pharmacists who worked in morning and afternoon shifts in all pharmacies in Hamadan city (82 pharmacies) were studied. A scenario was designed and based on it, a trained person (the researcher) presented to the pharmacies and after identifying the pharmacists, he gave his prescription to them. The prescription medications include warfarin, pantoprazole, enalapril, coenzyme $\mathrm{Q}_{10}$, and citalopram. Interactions of these medications were in the risk rating of class c (the interactions are at medium level and need to be controlled and monitored) according to the on-line LEXICOMP ${ }^{\circledR}$ platform (Lexi-interact).

A questionnaire containing criteria for assessing the pharmacist performance against DDI was used. The questionnaire was completed by the researcher (supposed patients) based on his observations. The first criterion was "the presence of a pharmacist in the pharmacy and recognizable from other personnel" based on his/her white coat with identification label and special place of him/her. The second criterion was "whether the pharmacist asks the patient's reason for visiting a physician". The third criterion was "whether the pharmacist checks the prescription drugs and then delivers them to the patient". Blood test to measure prothrombin time $(\mathrm{PT})$ and the international normalized ratio
(INR) is necessary for patients taking warfarin. Therefore, the fourth criterion was "whether pharmacist asks for the PT and INR tests and the presence of bleeding symptoms". The fifth criterion was "the pharmacist consulting about the proper use of each medication". Since the principal objective of this study was to evaluate pharmacists' performance against DDI and FDI, the sixth criterion was "whether the pharmacist consults about the food (Ginger, Gingko, Green Tea, vitamin K-containing foods such as Lettuce, Spinach, Cabbage, Garlic etc.) (Kalantari et al., 2007) and drugs (Pantoprazole, Enalapril, Coenzyme $\mathrm{Q}_{10}$, Citalopram and Cromolyn Sodium) (Harchegani et al., 2017) interactions with warfarin". The seventh criterion was "whether the pharmacists check the drug interactions by referring to existing databases".

\section{Statistical analysis}

After gathering the Data, it was coded and analyzed using the statistical software SPSS 20. A t-test was used for matching two groups for some variables. A $p$-value of less than 0.05 was considered as statistical significant.

\section{RESULTS}

Pharmacists were present in 67 out of 82 studied pharmacies $(81.7 \%)$ and 48 of them $(71.6 \%)$, were recognizable (Table 1). Only 27 (40.3\%) pharmacists asked the patient's reason for visiting a physician (Table 1). Assessing the pharmacist's performance in checking the medications and then delivering them to the patient showed that 37 pharmacists $(55.2 \%)$ had this criterion. Twenty-two pharmacists $(32.8 \%)$ checked the prescription medications for probable interactions and $47(67.2 \%)$ of them did not. Sixteen pharmacists $(23.9 \%)$ gave consultation about the PT and INR tests and 15 pharmacists $(22.4 \%)$ gave consultation about the bleeding symptoms due to misusing of warfarin, 42 pharmacists $(62.7 \%)$ gave advice about the medications intake time while 25 pharmacists $(37.3 \%)$ did not give such an advice. Sixteen pharmacists $(23.9 \%)$ gave consultation about the interaction of warfarin with vitamin $\mathrm{K}$ containing foods such as spinach, green tea, and etc. (Table 1). Additionally, 63 pharmacists (94.0\%) gave advice about the interaction of warfarin with another drug such as pantoprazole. However, only 8 pharmacists $(9.8 \%)$ checked the DDI and FDI with warfarin by referring to the existing databases and 59 of them did not $(90.2 \%)$ (Table 1$)$.

Table 1: The frequency of the studied criteria in the studied pharmacies.

\begin{tabular}{|c|c|c|c|c|c|c|}
\hline \multirow{2}{*}{ Variable } & \multicolumn{2}{|c|}{ Yes } & \multicolumn{2}{|c|}{ No } & \multicolumn{2}{|c|}{ Total } \\
\hline & Frequency & $\%$ & Frequency & $\%$ & Frequency & $\%$ \\
\hline Presence of a pharmacist in the pharmacy & 67 & 81.7 & 15 & 18.3 & 82 & 100 \\
\hline Pharmacist is distinguishable from other personnel. & 48 & 71.6 & 19 & 28.4 & 67 & 100 \\
\hline The pharmacist asks the patient's reason for visiting a physician & 27 & 40.3 & 40 & 59.7 & 67 & 100 \\
\hline The pharmacist checks the medications and then deliver them to the patient & 37 & 55.2 & 30 & 44.8 & 67 & 100 \\
\hline The pharmacist pays attention to interactions in the prescription & 22 & 32.8 & 45 & 67.2 & 67 & 100 \\
\hline The pharmacist gives advice about PT and INR tests. & 16 & 23.9 & 51 & 76.1 & 67 & 100 \\
\hline The pharmacist gives advice about bleeding symptoms & 15 & 22.4 & 52 & 77.6 & 67 & 100 \\
\hline The pharmacist gives advice about the warfarin intake time & 42 & 62.7 & 25 & 37.3 & 67 & 100 \\
\hline The pharmacist gives advice about warfarin interactions with vitamin $\mathrm{K}$-containing foods & 16 & 23.9 & 51 & 76.1 & 67 & 100 \\
\hline The pharmacist checks the warfarin interactions by referring to existing databases. & 8 & 9.8 & 59 & 88.1 & 67 & 100 \\
\hline
\end{tabular}


The professional performance of pharmacists is the result of academic knowledge and professional in the pharmacy. Since in the population of the pharmacists studied, they all had the doctorate degree in pharmacy (Pharm.D.) from the medical universities of Iran, and successfully passed the same courses of study with the same content and educational titles, pharmacists were evaluated based on criteria of their work experience at the pharmacy. Accordingly, 29 of the pharmacists (43.28\%) had a work experience of $0-5$ years, while the others had a history of technical responsibility for more than five years $(56.72 \%)$. In the field of drug interactions in the prescription, from 29 pharmacists with a work experience of 0-5 years, 7 pharmacists $(24.13 \%)$ identified and mentioned drug interactions. Among 38 pharmacists with more than 5 years of experience, $15(39.47 \%)$ did not mention the drug interactions in the prescription. Among 38 pharmacists with more than 5 years of experience, 11 pharmacists $(38.94 \%)$ provided counseling about the interaction of warfarin with foods containing vitamin $\mathrm{K}$, including lettuce, spinach, and cabbage. Five pharmacists with the work history of $0-5$ years $(17.24 \%)$ advised on interactions with foods (Figure 1).

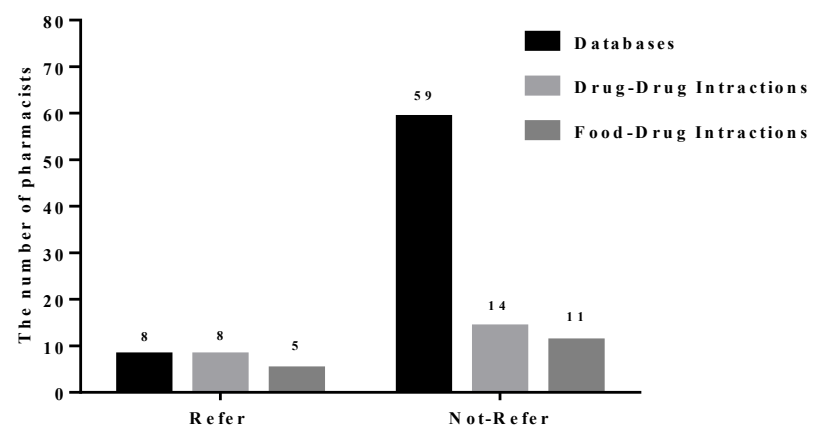

Fig. 1: The relationship between the recognition of drug interactions and the pharmacist's experience. Each column with a distinct color indicates the number of pharmacists with a characteristic specified on the right side of the figure.

In this study, only 8 of 67 pharmacists (11.49\%) reviewed databases (software systems as clinical decision support resources), all 8 pharmacists (100\%) mentioned the drug interactions contained in the prescription. 59 pharmacists of 67 pharmacists $(80.05 \%)$ did not use information sources or did not have access to information resources. Among 59 pharmacists who did not use information resources to investigate drug interactions, $14(23.72 \%)$ identified and reported drug interactions.

Among 8 pharmacists referred to databases, 5 pharmacists $(62.5 \%)$ provided counseling about the interaction of warfarin with foods containing vitamin $\mathrm{K}$, including lettuce, spinach, and cabbage. Eleven pharmacists not referring to databases, (18.64\%) advised on interactions with foods (Figure 2).

\section{DISCUSSION}

Medication errors as one of the most important physician mistakes kill thousands of patients in the world (Cohen and Smetzer, 2017; Walsh et al., 2017). In Iran, various studies indicated the increased rate of DDI in the prescriptions (Sheikhol Eslami and Asefzadeh, 1999). The treatment team's knowledge of potential interactions and the mechanism of them results in significant reduction of such interactions, however, it is not possible to prevent all of these interactions (Lima and Cassiani, 2009). This study was aimed to evaluate the pharmacists' performance regarding DDI and FDI. At the beginning of the study, there were 101 pharmacies in Hamadan, of which only 82 pharmacies were active during the study period. In a study by Eslami et al. (2017) in Ahwaz, the professional practice of pharmacists working at pharmacies in dealing with drug prescriptions was studied in 120 pharmacies (Elsami et al., 2017). In another study by Mostafavi et al. (2013), a total of 146 community pharmacists in Isfahan city, Iran, were randomly selected for the study on the professional practice (dispensing accuracy and counseling) of pharmacists working at pharmacies (Mostafavi et al., 2013). In a study on the community pharmacists' professional behavior in dealing with anti-diabetes and anti-asthma prescriptions in the United Arab Emirates, 192 pharmacies from the nearly 400 pharmacies in the United Arab Emirates were included in the study (Alomar et al., 2011). Therefore, considering that the number of samples (pharmacies) depends on the vastness of the city, the population of the city and the number of pharmacies in the city, it can be concluded that the sample size in the present study was consistent with other studies in different cities of Iran and other countries.

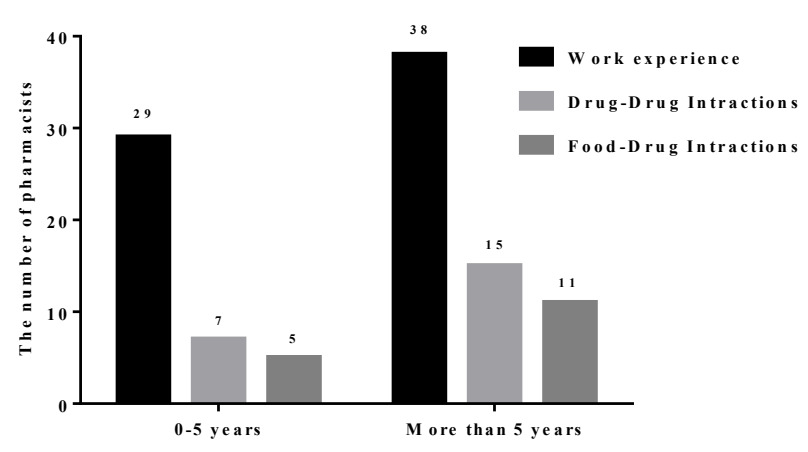

Fig. 2: The relationship between using resources and check DDI/FDI. Each column with a distinct color indicates the number of pharmacists with a characteristic specified on the right side of the figure.

In 2017, 226 pharmacists worked in the city of Hamadan. Of these, 130 were active at various shift times (morning, evening, or night) at governmental and private pharmacies. About 50 pharmacists were employed in hospital pharmacies, and other pharmacists were employed in other related businesses such as pharmaceutical companies, drug distribution companies, administrative and management affairs, and so on.

The presence of pharmacists in their pharmacies is one of their duties. In the present study, about $82 \%$ of the pharmacists were present in their pharmacies and 48 of them $(71.6 \%)$ were recognizable from other personnel. Different findings were reported by others (Mostafavi et al., 2013; Al-Arifi, 2012) which may be because of the different numbers of studied pharmacies, the level of inspection of pharmacies by the relevant authorities in different studied cities, the differences in the studied populations and their demographic characterizations (population, education, welfare, etc.) (Al-Arifi, 2012), the different number of patients (prescriptions) and performing the studies at different times during a day. However, both international and Iranian laws require the presence of pharmacists at the prescribed times in their pharmacies and being distinguishable from other personnel by 
specific symbols (label, white coat, special place, etc.).

The prevention of medication errors is another duty of pharmacists. In this study, only $40.3 \%$ of pharmacists asked the patients' reason for visiting a physician. Furthermore, $55.2 \%$ of the pharmacists checked the prescription and after assessing its contents, deliver it to the patient. Other studies reported different findings that may be because of the differences in pharmacies' workloads, which in turn are affected by the location of the pharmacy, time of patient referring and the specialty of the pharmacist (Oparah and Arigbe-Osula, 2002).

However, pharmacists have been trained for the abovementioned factors and based on the regulations the patients have the right to be aware of the presence of the pharmacist in the pharmacy and on the other hand, the pharmacist has to give the medication information to the patients. The pharmacistpatient relationship depends on the patients' awareness of the responsibilities of pharmacists, behavioral characteristics of the patient (shyness, fear of inappropriate questions, etc), patients' awareness of their rights, pharmacy traffic, and the lack of enough space in pharmacies (Hargie et al., 2000).

The drug interactions in the prescriptions are inevitable (Holbrook et al., 2005; Rashidi and Senoubar, 2005). Our findings showed that about $33 \%$ of the pharmacists checked the prescription for drug interactions. In previous studies reported that drug consultations were $30.43 \%$ for cough, $21.47 \%$ for diarrhea, and $30.43 \%$ for cold (Schwartzberg et al., 2007). Treatment with Warfarin is monitored with INR test (which is determined by PT) and consultation about bleeding symptoms (Firriolo and Hupp, 2012). In the present study, $24 \%$ of pharmacists gave consultation about INR test and 22.4\% advised about bleeding symptoms, respectively. According to our findings, Mostafavi et al. reported that only $18.4 \%$ of pharmacists inform patients about warfarin side effects (Mostafavi et al., 2013). Training of medical staff and patients about the side effects of warfarin and DDI and FDI as well as PT and INR tests can prevent unwanted side effects and re-hospitalization of the patients (Tang et al., 2003).

Coenzyme Q10 diminish the effect of warfarin and thus the administration of them should be done under medical supervision (Saunders, 2004). Citalopram is one of selective serotonin reuptake inhibitors (SSRI) which is prescribed for depression and anxiety that may increase bleeding (Saunders, 2004). In the present study, the performance of pharmacists in giving advice about the medications intake times was investigated (take warfarin at the same time each day). About 63 of the pharmacists gave advice about DDI and $24 \%$ advised about FDI. In a study conducted in Isfahan city, only $3.7 \%$ of the studied pharmacists gave advice about drug interactions with warfarin which was significantly lower than that of our study. Similar to our findings that about $75 \%$ of the pharmacists did not give advice about food interactions with warfarin. Mostafavi, et al. reported that none of 136 studied pharmacists gave such an advice. However, it is obvious that drug interactions are very important and may result in drug toxicity and re-hospitalization of the patients (Mostafavi et al., 2013).

Warfarin has important interaction with PPIs (Labenz et al., 2003). In the present study, $94.0 \%$ of the pharmacists gave consultants about the interactions of these medications. In line with our findings, other studies reported that $98.5 \%$ of pharmacists gave advice about pantoprazole interaction (Flynn et al., 2009). In this study, only $9.8 \%$ of the studied pharmacists checked the DDI and FDI by referring to the existing databases. It is believed that getting help from drug interaction software is more useful than the pharmacist performance alone (Barrons, 2004). According to the possible lack of pharmacist remembering, the use of such practical software can improve his/her performance. Unfortunately, in the present study, more than $90 \%$ of the pharmacists did not use any databases to check DDI and/or FDI suggesting paying more attention to this important issue.

\section{CONCLUSIONS}

Logical prescription of medications has an important role in patient treatment. One important problem in this regard is DDI and FDI that impose a lot of costs for patients and country. Since pharmacist is in direct dealing with patients, their performance can lead to treatment speed-up, prevent from patients' re-hospitalization, and economic efficiency. Thus, training pharmacist students, holding workshops, more authority inspections, and inform people via media are recommended to improve the current status of pharmacists' performance.

\section{CONFLICT OF INTEREST}

The authors declared that they have no conflict of interest.

\section{ETHICAL CONSIDERATIONS}

The study was approved by the Ethical Committee of Hamadan University of Medical Sciences (approval number: IR.UMSHA.REC.1395.08).

\section{LIMITATIONS OF THE STUDY}

Although the research has reached its aims, there were some unavoidable limitations. First, this study was done with a specific prescription, so the results cannot be generalized to all prescriptions. Also, this study was conducted in a city (Hamadan) with its specific features and it is to conclude that similar results may be achieved all over the country; extending the results to other cities within the country or to other parts of the world is subject to limitations. But it's noticeable as a start for discussing the errors that may occur in pharmacies. Moreover, in this research, the prescription was not selected randomly, but the selected drugs were drugs which can cause serious complications if not presented correctly.

\section{ACKNOWLEDGMENT}

This research was funded by a grant from Hamadan University of Medical Sciences, vice chancellor for research affairs (Project No: 9410015220). The authors wish to thank them for their financial support.

\section{REFERENCES}

Al-Arifi MN. Patients' perception, views and satisfaction with pharmacists' role as health care provider in community pharmacy setting at Riyadh, Saudi Arabia. Saudi Pharmaceutical Journal, 2012; 20(4):32330 .

Alizadeh A, Rostamian A, Saeedpour K, Hemmati M, Khorasani Z, Mohagheghi M, et al. Drug interactions frequency in the bedridden patients in three hospitals of Tehran city. Modern Care Journal, 2011; 
$7(3): 22-7$

Alomar MJ, Qandil S, Al-Hilwani HMA, Malkat DM, Caroline C. Evaluation of the community pharmacist's behavior towards a prescription of antidiabetic and antiasthma drugs. Pharmacy Practice, 2011; 9(1):37-43.

Barrons R. Evaluation of personal digital assistant software for drug interactions. American journal of health-system pharmacy, 2004; 61(4):380-385.

Cohen MR, Smetzer JL. ISMP Medication Error Report Analysis. Hospital Pharmacy, 2017; 52(2):91-3.

De Almeida SM, Gama CS, Akamine N. Prevalence and classification of drug-drug interactions in intensive care patients. Einstein, 2007; 5:347-51.

Elsami K, Alboghobeish S, Makhmalzadeh BS. Evaluating the Professional Practice of Pharmacists Working at Pharmacies in Dealing with Drug Prescriptions. J Clin Res Bioeth, 2017. 8(4):310-317.

Firriolo FJ, Hupp WS. Beyond warfarin: the new generation of oral anticoagulants and their implications for the management of dental patients. Oral surgery, oral medicine, oral pathology and oral radiology, 2012; 113(4):431-41.

Flynn EA, Kenneth NB, Berger BA, Lloyd KB, Brackett PD. Dispensing errors and counseling quality in 100 pharmacies. Journal of the American Pharmacists Association, 2009; 49(2):171-82.

Harchegani AL, Hemmati AA, Nili-Ahmadabadi A, Darabi B, Shabib S. Cromolyn Sodium Attenuates Paraquat-Induced Lung Injury by Modulation of Proinflammatory Cytokines. Drug research, 2017; 67(5):283-8.

Hargie OD, Morrow NC, Woodman C. Pharmacists' evaluation of key communication skills in practice. Patient Education and Counseling, 2000; 39(1):61-70.

Holbrook AM, Pereira JA, Labiris R, McDonald H, Douketis JD, Crowther M, et al. Systematic overview of warfarin and its drug and food interactions. Archives of internal medicine, 2005; 165(10):1095-106.

Hughes RG, Ortiz E. Medication errors: why they happen, and how they can be prevented. Journal of infusion nursing, 2005; 28:14-24.

Kalantari H, Larki A, Latifi SM. The genotoxicity study of garlic and pasipy herbal drops by peripheral blood micronucleus test. Acta physiologica Hungarica, 2007; 94(3):261-6.

Labenz J, Petersen K, Rösch W, Koelz H. A summary of Food and Drug Administration-reported adverse events and drug interactions occurring during therapy with omeprazole, lansoprazole and pantoprazole. Alimentary pharmacology \& therapeutics, 2003; 17(8):1015-9.

Lima REF, Cassiani SHDB. Potential drug interactions in intensive care patients at a teaching hospital. Revista latino-americana de enfermagem, 2009; 17(2):222-7.
Mehrpooya M, Eshraghi A, Rabiee S, Larki-Harchegani A, Ataei S. Comparison the Effect of Fish-Oil and Calcium Supplementation on Treatment of Primary Dysmenorrhea. Reviews on recent clinical trials, 2017; 12(3):148-53.

Mostafavi SA, Pharm MC, Pharm EK. Evaluating the Professional Practice of Pharmacists Working at Pharmacies in Isfahan City, Iran. Journal of Isfahan Medical School, 2013; 31(237):690-700.

Oparah AC, Arigbe-Osula EM. Evaluation of Community Pharmacists' Involvement in Primary Health Care. Tropical Journal of Pharmaceutical Research, 2002; 1(2):67-74.

Pleuvry BJ. Pharmacodynamic and pharmacokinetic drug interactions. Anaesthesia \& Intensive Care Medicine, 2005; 6(4):129-33.

Rashidi K, Senoubar TN. Assessment of drug interactions in medical insurance prescriptions in Kurdistan province in 2000. Scientific Journal of Kurdistan university of medical sciences, 2005; 10(3):78-84.

Saunders DJ. Adverse drug reactions as cause of admission to hospital: Not all drugs that cause adverse reactions are actually prescribed by doctors. British Medical Journal, 2004; 329(7463):459.

Schwartzberg JG, Cowett A, VanGeest J, Wolf MS. Communication techniques for patients with low health literacy: a survey of physicians, nurses, and pharmacists. American journal of health behaviour, 2007; 31(1):S96-S104.

Sheikhol Eslami H, Asefzadeh S. Antibiotics in Qazvin physicians' prescriptions. J Med Faculty, Guilan Uni Med Sci, 1999; 8:31-2.

Tang EOY, Lai CS, Lee KK, Wong RS, Cheng G, Chan TY Relationship between patients' warfarin knowledge and anticoagulation control. Annals of Pharmacotherapy, 2003; 37(1):34-9.

Valizadeh F, Ghasemi S-F, Najafi S-S, Delfan B, Mohsenzadeh A. Errors in medication orders and the nursing staff's reports in medical notes of children. Iranian Journal of Pediatrics, 2008; 18(Suppl 1):33-40.

Walsh EK, Hansen CR, Sahm LJ, Kearney PM, Doherty E, Bradley CP. Economic impact of medication error: a systematic review. Pharmacoepidemiology and drug safety, 2017; 26(5):481-97.

How to cite this article:

Larki-Harchegani A, Mehrpooya M, Qadermazi A, Shabib S, Ataei S. Evaluation the professional Practice of community pharmacists in dealing with important drug interactions in prescription. J App Pharm Sci, 2018; 8(05): 129-133. 